\title{
A LOW POWER LOW COST 2.45 GHz ECRIS FOR THE PRODUCTION OF MULTIPLY CHARGED IONS
}

\author{
M. Schlapp', R. Trassl', M. Liehr ${ }^{3}$ and E. Salzborn ${ }^{2}$ \\ 'Argonne National Laboratory, Argonne, IL 60439 \\ 2 Institut fuer Kernphysik, Strahlenzentrum, JU Giessen, Germany \\ ${ }^{3}$ Leybold-Heraeus, Hanau, Germany
}

Abstract

A low cost, low power ECR ion source designed for the use on a high voltage platform with limited electrical power available, has been developed. To reduce the power consumption of the source the radial and axial magnetic confinement are produced entirely by permanent magnets. An axial magnetic mirror ratio of 2.7 is obtained by a configuration of two times four block magnets. A radial magnetic field of $0.5 \mathrm{~T}$ inside the plasma chamber of 60 $\mathrm{mm}$ inner diameter is produced by a hexapole magnet. Microwave power up to 300 watts $\mathrm{c} / \mathrm{w}$ can be applied to the plasma by using different slow-wave structures which allow the use of a plasma chamber much smaller in diameter than required by the wavelength of the used frequency of $2.45 \mathrm{GHz}$. The ion source can be operated in different modes either for producing multiply charged ions with intensities up to several hundred $\mathrm{e} \mu \mathrm{A}$ or for the production of high intensity beams of singly charged ions, i.e. $6.5 \mathrm{~mA}$ of $\mathrm{He}^{+}$. Applications for the ion source are in crossed beams experiments and as injectors for small accelerators as well as for spectroscopic investigations in the VUV wavelength region.

\section{SOURCE DESCRIPTION}

The main features of the described $2.45 \mathrm{GHz}$ ECR ion source as shown in Fig. 1 are low set up costs, low electrical power consumption due to the use of permanent magnets to produce the minimum-B-structure and two different operation modes for the production of multiply charged ions or the production of high intensities of singly charged ions. A detailed description of the ion source with different microwave injection lines is given elsewhere $[1,2]$. The figure shows the mechanical set up of the ion source including parts of the microwave system: the combined high-voltage/vacuum window and the transition from rectangular waveguide to coaxial line.

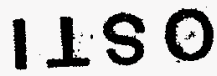

L6b) $<07 n r$

뵄ㅋㅂ

\section{I Magnetic System}

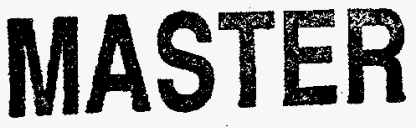

The magnetic system is made from high remanence $(1.12 \mathrm{~T})$, high coercivity $(1920 \mathrm{kA} / \mathrm{m}) \mathrm{NdFeB}$ permanent magnet material. It consists of two radially magnetized rings (each consists of 6 block magnets) producing an axial magnetic field of $2.14 \mathrm{kG}$ at the maximum with a mirror ratio of 2.85 . The hexapole magnet for the radial component is made from the same block magnets and induces a maximum radial magnetic field of $5 \mathrm{kG}$ inside the plasma chamber of $60 \mathrm{~mm}$ inner diameter.

\subsection{Microwave System}

An inexpensive magnetron amplifier based microwave system operating at $2.45 \mathrm{GHz}$ was chosen. The magnetron amplifier, which is pretty similar to the ones in microwave ovens, can produce up to 300 watts of microwave power in $\mathrm{c} / \mathrm{w}$-mode and is connected to a waveguide system [2]. The high voltage vacuum transition uses PTFE as the insulating material: Calculating the attenuation in a circular waveguide for $2.45 \mathrm{GHz}$ the smallest plasma cavity would be $9.5 \mathrm{~cm}$ in inner diameter, allowing both basic modes $\left(\mathrm{TE}_{11}\right.$ and $\left.\mathrm{TM}_{01}\right)$ to penetrate the plasma chamber with an attenuation of less than $0.1 \mathrm{~dB} / \mathrm{m}$ $[3,4]$. To reduce the physical size of the ion source different slow wave structures have been used to launch the microwave into the plasma. A detailed description of a Lisitano-Coil used as an antenna in a previous version has been given earlier $[1,5]$. In this paper the use of a helical antenna will be described. As shown in fig. 1 the antenna results from the inner conductor of a coaxial line. The characteristics of radiation of a helical antenna is given by the ratio of circumference of one turn to the free space wavelength $\left(V / \lambda_{0}\right)$ and by the distance between two turns (the angle between the turns and the axial direction has to be 12 to 14 degrees). The circumference of one turn has to be close to the free space wavelength $(123 \mathrm{~mm})$. In case of a diameter of the antenna between $\mathrm{D}=0.75 * \lambda_{0} / \pi$ and

> 


\section{DISCLAIMER}

This report was prepared as an account of work sponsored by an agency of the United States Government. Neither the United States Government nor any agency thereof, nor any of their employees, make any warranty, express or implied, or assumes any legal liability or responsibility for the accuracy, completeness, or usefulness of any information, apparatus, product, or process disclosed, or represents that its use would not iniringe privately owned rights. Reference herein to any specific commercial product, process, or service by trade name, trademark, manufacturer, or otherwise does not necessarily constitute or imply its endorsement, recommendation, or favoring by the United States Government or any agency thereof. The views and opinions of authors expressed herein do not necessarily state or reflect those of the United States Government or any agency thereof. 


\section{DISCLAMIER}

Portions of this docament may be illegible in electronic image products. Images are produced from the best available original document. 


\section{R26 waveguide}

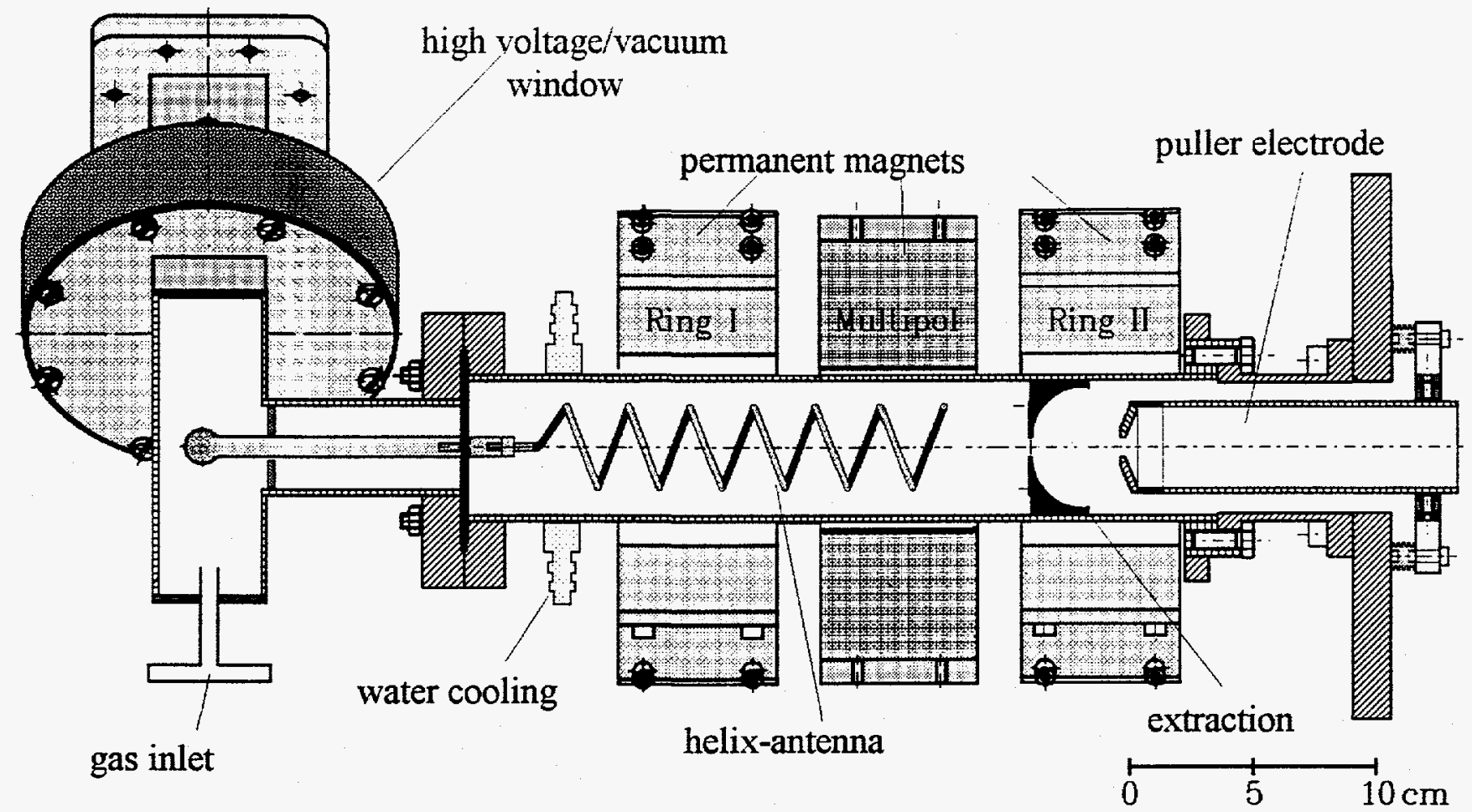

Fig. 1: Mechanical set up of the $2.45 \mathrm{GHz}$ ECRIS

$D=1.35 * \lambda_{0} / \pi$, the helical structure operates in a mode $T 1$ with negligible attenuation. Using these parameters, circular polarized waves are radiated in an axial direction. The directivity of the antenna increases with the number of turn as does the degree of polarization. The angle at Half Power Beam Width is given by $\Theta=105 / \mathrm{n}$, with $\mathbf{n}$ representing the number of turns [6,7]. For this application seven turns with an outer diameter of $41 \mathrm{~mm}$, using a $3 \mathrm{~mm}$ diameter wire have been chosen. That allows to use a plasma chamber much smaller in diameter with respect to the smallest circular waveguide.

\section{EXPERIMENTAL RESULTS}

\subsection{Production of Multiply Charged Ions}

The ion source has been operated using the helical antenna for the production of multiply charged ions. Fig. 2 shows a mass analyzed spectrum for Argon at an extraction voltage of $12.5 \mathrm{kV}$. The intensities were measure in a 20 $\mathrm{mm}$ diameter Faraday cup at approximately $1.5 \mathrm{~m}$ from the extraction aperture after a $45^{\circ}$ analyzing magnet. The source parameters were 240 watts of microwave power at a gas pressure of $3.6 * 10^{-6} \mathrm{mbar}$, measured in a vacuum chamber outside the puller electrode. Maximum obtained beam currents for other gases are shown in Table 1 at comparable source parameters.

\begin{tabular}{r|c|c|c|c} 
Charge State & ${ }^{14} \mathrm{~N}$ & ${ }^{16} \mathrm{O}$ & ${ }^{20} \mathrm{Ne}$ & ${ }^{40} \mathrm{Ar}$ \\
\hline 1 & 210 & 150 & 133 & 68.2 \\
2 & 11.5 & 14.2 & 98 & 58.8 \\
3 & 0.16 & 0.27 & 8 & 11.5 \\
4 & 0.01 & 0.017 & 0.11 & 1.2 \\
5 & $/$ & $/$ & 0.028 & 0.2
\end{tabular}

Table 1: Beam currents for different charge states and gases in $\mathrm{e} \mu \mathrm{A}$

\subsection{High Intensities of Singly Charged lons}

In a second mode of operation we studied the production of high intensities of singly charged ions, namely $\mathrm{He}^{+}$. Using a modified axial magnetic confinement with maxima at $1.75 \mathrm{kG}$ and a mirror ratio of 2.15 . The magnetic field maxima could be varied on-line by changing 


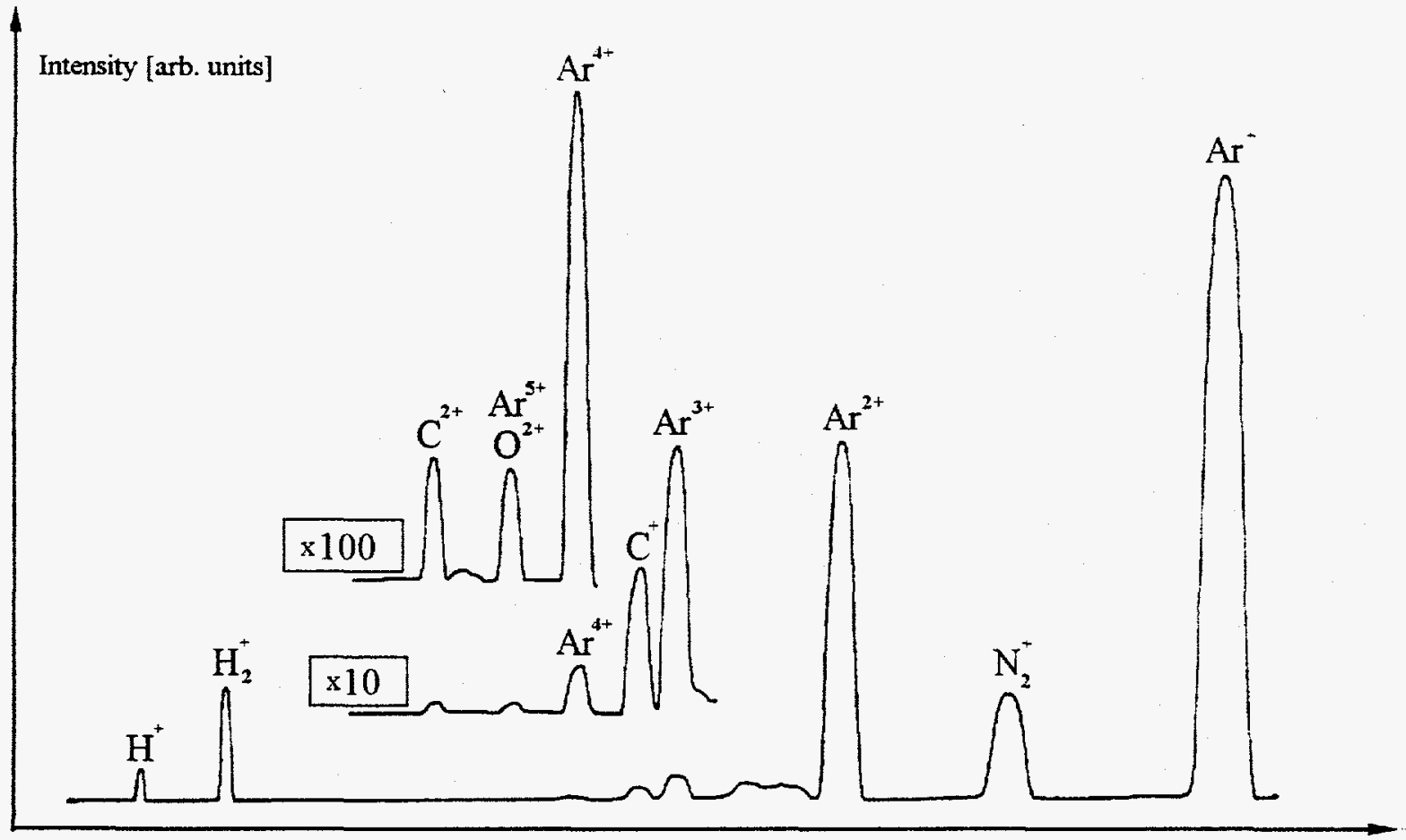

Magnetic Field [arb. units]

Fig. 2: Mass analyzed ${ }^{* 0} \mathrm{Ar}$ spectrum obtained at $12.5 \mathrm{kV}$ extraction voltage.

the radii of the axial rings and have been optimized to the above value. With this set up, a $\mathrm{He}^{+}$beam of $6.5 \mathrm{~mA}$ at an extraction voltage of $20 \mathrm{kV}$ could be obtained. The microwave power applied was 225 watts. Gas pressure during the run was $2.1 * 10^{-5} \mathrm{mbar}$ in a vacuum chamber outside the puller electrode and $3 * 10^{-2} \mathrm{mbar}$ at the gas inlet of the ion source. All vacuum readings are corrected for Helium. The beam was measured in a $20 \mathrm{~mm}$ diameter Faraday cup, $1.5 \mathrm{~m}$ from the extraction aperture of $10 \mathrm{~mm}$ diameter. An Einzel lens (46 $\mathrm{mm}$ diameter) mounted directly behind the puller electrode was used as a beam focusing element. The diameter of the ion beam $\left(\mathrm{U}_{\mathrm{exx}}=20 \mathrm{kV}, \mathrm{U}_{\mathrm{ex}}=17 \mathrm{kV}\right)$ was measured to be $3.2 \mathrm{~mm}$ at a $90 \%$ emmittance of $76 \pi \mathrm{mm}$ mrad. The emittance was measured employing the slit-wire technique [8].

\section{DISCUSSION AND OUTLOOK}

The production of highly charged ions in an ECR plasma shows possible spectroscopic applications, especially in the vacuum-ultraviolet (VUV) region of the spectral range [9]. To enhance the performance for the production of multiply charged ions a new magnetic structure has been designed, producing higher mirror ratios.

\section{ACKNOWLEDGMENTS}

This work was supported by US D.O.E. Nuclear Physics Division under contract W-31-109-ENG-38.

\section{REFERENCES}

[1] M. Liehr, R. Trassl, M. Schlapp, E. Salzborn, Rev. Sci. Instrum. 63 (4) (1992) 2541

[2] M. Schlapp et al., 5th Intern. CASOSALP, Meudon, France (1995) 182

[3] G.L. Ragan, Microwave Transmission Circuits, McGraw-Hill (1948)

[4] T.S. Laverghetta, Microwave Measurements and Techniques, Artech (1974)

[5] G. Lisitano, 9th Intern. Symposium on Plasma Chemistry, Pugnochiuso, Italy (1989)

[6] GJ.D. Kraus, Antennas, McGraw-Hill (1988) 271

[7] H. Meinke, F.W. Gundlach, Taschenbuch der Hochfrequenztechnik, Springer Verlag Berlin (1986)

[8] W. Krauss-Vogt, Ph.D. Thesis, Jülich (1985) Jül-2043

[9] M. Schlapp et al., 12th Intern. Workshop on ECRIS, RIKEN, Japan (1995) 71 